\title{
Correction to: Keeping pace with the healthcare transformation: a literature review and research agenda for a new decade of health information systems research
}

\author{
Nadine Ostern ${ }^{1} \cdot$ Guido Perscheid $^{2} \cdot$ Caroline Reelitz $^{2} \cdot$ Jürgen Moormann ${ }^{2}$
}

Published online: 20 December 2021

(c) The Author(s), under exclusive licence to Institute of Applied Informatics at University of Leipzig 2021

\section{Correction to: Electronic Markets}

https://doi.org/10.1007/s12525-021-00484-1

In this article the affiliation of authors are incorrect. Given here are the correct affiliations.

The original article has been corrected.

Publisher's note Springer Nature remains neutral with regard to jurisdictional claims in published maps and institutional affiliations.

The original article can be found online at https://doi.org/10.1007/ s12525-021-00484-1.

Nadine Ostern

nadine.ostern@wiwi.uni-marburg.de

Guido Perscheid

g.perscheid@fs.de

Caroline Reelitz

c.reelitz@fs.de

Jürgen Moormann

j.moormann@fs.de

1 Chair for Digitalization and Process Management, PhilippsUniversity Marburg, Universitätsstraße 24, 35037 Marburg, Germany

2 Frankfurt School of Finance \& Management, ProcessLab, Adickesallee 32-34, 60322 Frankfurt am Main, Germany 